\title{
Memórias em trânsito - as ditaduras brasileira e argentina em três romances brasileiros contemporâneos
}

\author{
Memories in transit - the Brazilian and Argentinean dictatorships in three contempo- \\ rary Brazilian novels \\ Cristiane CHECCHIA* \\ Universidade Federal da Integração Latino-Americana (UNILA)
}

\begin{abstract}
RESUMO: Mediante a vigorosa máquina de silêncio que se impôs até recentemente no Brasil a respeito da última ditadura, tornou-se recorrente pensar nossos processos de memória analisando-os em comparação aos demais países do Cone Sul. Entre a análise do conjunto da região e a singularidade nacional, o processo brasileiro revela-se frequentemente "por subtração", a partir do que não foi feito em relação aos vizinhos, sobretudo em relação à Argentina. À luz da política revisionista e autoritária do atual governo, este artigo se propõe a especular sobre os desdobramentos de nossos processos bloqueados de memória e como tais bloqueios podem ser enfrentados por uma memória em trânsito, mobilizada literariamente na conexão das histórias recentes do Brasil e da Argentina, a partir da leitura de três romances brasileiros publicados recentemente: Pessoas que passam pelos sonhos, de Cadão Volpato (2013), A resistência, de Julián Fuks (2015) e Mar azul, de Paloma Vidal (2012).
\end{abstract}

PALAVRAS-CHAVE: estética e política; memória social; esquecimento; Paloma Vidal; Julián Fuks; Cadão Volpato

ABSTRACT: Through the vigorous machine of silence that was imposed until recently in Brazil regarding the last dictatorship, it has become recurrent to think about our memory processes in comparison to the countries of the Southern Cone. Between the analysis of the whole region and the national uniqueness, the Brazilian process often turns out to be "by subtraction", based on what was not done in relation to neighbors, especially Argentina. In light of the revisionist and authoritarian policy of the current government, this article proposes to speculate about the developments of our blocked memory processes and how such blockages can be faced by a memory in transit, mobilized literarily in the connection of recent stories from Brazil and Argentina, from the reading of three recently published Brazilian novels: Pessoas que passam pelos sonhos, by Cadão Volpato (2013), A resistência, by Julián Fuks (2015) and Mar azul, by Paloma Vidal (2012).

KEYWORDS: aesthetics and politics; social memory; forgetfulness; Paloma Vidal; Julián Fuks; Cadão Volpato

\footnotetext{
* Doutora em Letras (USP). Professora de Literatura do Instituto Latino-Americano de Arte, Cultura e 1 História (ILAACH) da UNILA e do Programa de Pós-Graduação Interdisciplinar em Estudos LatinoAmericanos (IELA-UNILA). E-mail: crischecchia@gmail.com
} 
Outro ano mais, e a ditadura finalmente agonizará, assim parece a todos; mas não será a agonia que precede a morte, será a metamorfose, lenta e autocontrolada.

$K$. Bernardo Kucinski

Somos exímios memoricidas. Giselle Beiguelman

\section{Pensar as memórias em trânsito}

Passadas cerca de três décadas do início do processo de redemocratização na Argentina e no Brasil, sabe-se que os caminhos pelos quais foram trilhadas as tentativas de reparação e as políticas da memória sobre o período ditatorial em cada um desses países é bastante distinta. Se no Brasil aparentemente nos deparamos com uma série de bloqueios ao estabelecimento de uma cultura da memória, na Argentina, por sua vez, houve um esforço coletivo e de diversas vozes, muitas vezes em conflito, para a elaboração do passado recente por meio de diferentes operações de reivindicação por verdade, memória e justiça.

Não obstante o recorte nacional ou comparativo que se pode imprimir na investigação sobre estes caminhos distintos e sobre o papel que a literatura assume em ambos os processos, interessa-me investigar uma memória em trânsito, mobilizada na conexão das histórias recentes dos dois países, entre cidades de ambos os lados da porosa fronteira e no cruzamento, ou no intervalo, entre dois idiomas. Este trabalho propõe assim a leitura de três romances publicados no Brasil recentemente, e com apenas pequeno intervalo entre si, cujos argumentos se desenvolvem neste trânsito, em fragmentos de relato, buscas fracassadas, vagas recordações: Pessoas que passam pelos sonhos, de Cadão Volpato (2013), A resistência, de Julián Fuks (2015) e Mar azul, de Paloma Vidal $(2012)^{1}$.

Vale dizer que do ponto de vista metodológico procurei trabalhar estas leituras atritando-as a materiais e discursos bastante heterogêneos, infiltrando-as com as angústias do presente e pensando-as a partir dos diferentes ritmos da memória social no Cone Sul. Para desenvolver tal leitura, compartilho das abordagens críticas contemporâneas

\footnotetext{
${ }^{1}$ As primeiras intuições que deram origem a este trabalho foram apresentadas no IX Congresso Brasileiro de Hispanistas, em 2016. Ver resumo disponível em https://dspace.unila.edu.br/bitstream/handle/123456789/2096/CadernodeResumos.pdf?isAllowed=y\&seq uence $=1$
}

Revista Moara, n. 56, vol. 1, ago-dez 2020 ISSN: 0104-0944 
que vêm procurando desestabilizar o entendimento que separa o estético, o político e o econômico em distintas esferas. Trabalho, portanto, a partir da ainda sugestiva perspectiva pós-autonômica, pensando-a como certo regime de leitura que desloca o foco do fenômeno (intra)literário para problematizar a "imaginação pública” (LUDMER, 2013) e, no caso, os múltiplos discursos que configuram a memória do passado recente no Brasil, atravessado-os com a experiência argentina. Tal escolha metodológica apresentou-se mediante as incertezas de fundo que pairam sobre as possibilidades de ler literatura e ler ficção em um presente que parece apontar para o esgotamento do pacto democrático que sustentou nossa transição.

Na primeira parte do artigo desenvolvo uma análise comparativa sobre os processos de memória no Brasil e na Argentina. Na segunda parte, debruço-me brevemente sobre os argumentos dos três romances, para, por fim, sugerir o que poderia ser pensado como memórias em trânsito, a partir de considerações mobilizadas pela leitura.

\section{Duas cenas iniciais, para pensar a memória impedida}

A proposta deste trabalho surgiu a partir de muitas inquietações e da exploração de um corpus de obras cuja leitura me foi de modo incontornável atravessada por cenas perturbadoras que começaram a assombrar a vida pública nacional e regional há poucos anos.

Cito apenas duas destas cenas, a título de exemplo, que vieram a ter desdobramentos bastante distintos. A primeira delas é a homenagem prestada por um congressista em Brasília, hoje presidente do Brasil, em seu voto a favor do impeachment de Dilma Roussef, a um dos mais reconhecidos torturadores da ditadura brasileira: não bastasse a sucessão de manifestações em favor da tríade família, bíblia e pátria, a fala em favor do terror explicitava as linhas de continuidade e a impunidade dos crimes perpetrados por agentes do Estado no período da ditadura civil-militar brasileira, muitos deles ainda na ativa. $\mathrm{O}$ choque que muitos sentiram parecia advir da quebra de um tabu, inclusive por parte da direita mais conservadora: o de fazer referência direta e explícita, em rede nacinal, aos porões dos anos de chumbo. Certo da impunidade, aquele pronunciamento aos olhos do país inteiro parecia desestabilizar inclusive o pacto de silêncio e de esquecimento perpetrado pelos defensores do regime, revolvendo os restos que quiseram apa-

Revista Moara, n. 56, vol. 1, ago-dez 2020 ISSN: 0104-0944 
gar, mostrando as salas escuras onde foram (e onde são ainda) perpetradas torturas. Houve reações nos dias seguintes, cuja repercussão parece tímida diante do que significaram aquelas palavras gritadas na casa onde são debatidas as leis que devem regular a vida nacional: palavras que feriam os princípios mais básicos do respeito à condição humana. Aquele domingo amargo parecia, portanto, expor uma cesura entre duas épocas: de uma época em que determinadas coisas não deveriam ser ditas (ou, quando ditas, apareciam como uma espécie de resíduo inconveniente), para outra época em que a discursividade violenta e autoritária se afirmava como a de uma nova ordem emergente $^{2}$.

A outra cena a que me refiro circulou nas redes sociais quase à mesma época, dando-se a conhecer conforme o capricho dos algoritmos que controlam a circulação das informações na internet. Tratava-se de um protesto da classe artística argentina contra o então Ministro da Cultura da cidade de Buenos Aires. Algum tempo antes, em janeiro de 2016, este senhor havia declarado em uma entrevista que "no hubo 30 mil desaparecidos" e que este teria sido apenas um número estabelecido em uma mesa fechada, a fim de se acordarem indenizações ${ }^{3}$. Tais declarações mobilizaram no país uma forte onda de protestos organizados por diversos grupos e movimentos sociais argentinos (entidades de familiares, acadêmicos, artistas, sindicatos, associações profissionais) reivindicando a renúncia imediata do ministro, o que ele veio a fazer em julho daquele mesmo ano, alegando excesso de atividades em suas diferentes ocupações (como a direção do Teatro Colón). A estratégia utilizada nos protestos parece ser um elemento importante para entender sua eficácia, qual seja, deixar ressoar inúmeras vezes a declaração do ministro "no hubo 30 mil desaparecidos" 4 . Nas imagens a que tive oportunidade de assistir, essas palavras foram reproduzidas quase simultaneamente em todos os teatros de Buenos Aires da mesma forma: interrompia-se a sessão das peças e se ouvia o áudio com a voz e a declaração completa do ministro. Em seguida os atores liam o ma-

\footnotetext{
${ }^{2}$ É evidente que se poderia buscar outros exemplos, não apenas do próprio deputado diversas vezes antes, menos visíveis e mais recuados no tempo. De todo modo, o evento acontecido durante a primeira votação do impeachment, em sessão difundida pelas antenas de TV a milhões de domicílios, parecia efetivamente explicitar que algo estava mudando em uma escala inimaginável pouco tempo antes.

${ }^{3}$ Uma série de reportagens foramdifundidas na imprensa argentina a respeito dos protestos. Ver, por exemplo, "Los artistas contra Lopérfido", de Paula Sabatés. Página/12, 22 de mayo de 2016. Disponível em https://www.pagina12.com.ar/diario/sociedad/3-299962-2016-05-22.html

${ }^{4}$ Chamei brevemente a atenção, em nota, para este episódio no artigo em que discuto os embates pela memória no ensaio argentino (CHECCHIA, 2017, nota 21).
}

Revista Moara, n. 56, vol. 1, ago-dez 2020 ISSN: 0104-0944 
nifesto escrito coletivamente, exigindo sua renúncia. $\mathrm{O}$ fato de se ouvir em alto volume "no hubo 30 mil desaparecidos" parecia demandar palavras que se contrapusessem em praça pública àquele discurso. Muitos outros protestos foram realizados na Argentina ao longo de todo o primeiro semestre de 2016, muitos deles a partir da mesma estratégia que evidenciava o retrocesso que a ofensiva do governo macrista procurava impor a chaves básicas do que foi o entendimento coletivo conquistado na retomada da democracia no país. Fiquei imaginando se seria possível algo semelhante no Brasil. Por que as palavras do parlamentar não foram reproduzidas mil vezes, demandando de nós, um discurso veemente de confronto e de inconformidade por cada dia em que este senhor continuava a por os pés no congresso? A pergunta parece não fazer sequer algum sentido, à luz do fato de que não apenas nada aconteceu, como também o parlamentar foi eleito presidente dois anos depois.

O contraste que se explicita a partir destes dois episódios diz muito das diferenças conhecidas que opõem as políticas reparatórias (tanto no plano simbólico, quanto no plano jurídico) no Brasil e na Argentina, além de outras diferenças que dizem respeito aos regimes e às alianças que imperaram nas transições à democracia nos dois países. No conjunto dos países do Cone Sul, Brasil e Argentina poderiam ser vistos como dois extremos de um arco memória-silenciamento. Sugiro pensar que no Brasil a reivindicação de lembrar nosso passado recente acaba se dando por um exercício de subtração: muito frequentemente, tentamos entender nossos processos de memória amparados no recurso de investigar os processos na transição dos demais países do Cone Sul, e sobretudo na Argentina, para perceber o que não foi conquistado (ou apenas muito parcialmente) até agora no Brasil 5 .

A cartografia de todo o debate em ambos os países, Brasil e Argentina, estenderia em muito os limites deste artigo, ainda mais pelo fato de que o próprio desenho do mapa se mostra também um exercício conflituoso, como assinalou Dalmaroni (2004, p. 118). Mas arrisco apontar brevemente algumas linhas de força em cada um dos contextos.

\footnotetext{
${ }^{5}$ Algumas das análises historiográficas mais interessantes que parecem sugerir o que estou denominado como esse "exercício de subtração" estão nos trabalhos de Enrique Serra Padrós (2012), Carlos Fico (2013) e Caroline Silveira Bauer (2014).
}

Revista Moara, n. 56, vol. 1, ago-dez 2020 ISSN: 0104-0944 
$\mathrm{Na}$ Argentina, a passagem da primeira para a segunda metade os anos 80 foi marcada duplamente pela publicação e ampla difusão do informe Nunca Más, da CONADEP e pela conquista da realização dos juízos às Juntas Militares. ${ }^{6}$ Também foi fundamental que à narrativa de guerra e à retórica dos "dois demônios" se impusesse a interpretação, que se mostrou uma verdadeira revolução paradigmática, dos crimes cometidos pelo Estado como crimes de "violação aos direitos humanos". Para isso, por sua vez, foi preciso sublinhar a condição de vítimas das pessoas sequestradas, torturadas e mortas pelo aparato repressor estatal, independentemente das acusações a elas imputadas (JELÍN, 2018, p. 49, VEZZETTI, 2012). As diferentes e discordantes vozes do campo das esquerdas e mesmo de certas tendências liberais precisaram se reunir em uníssono repúdio ao terrorismo estatal, ainda que isso tenha implicado suspender momentaneamente a visibilidade dos terrenos de desacordo (SONDERÉGUER, 2001).

Apenas em meados dos anos 90, portanto, bem após o juízo às Juntas e a partir de certa estabilização de sentido em torno ao inaceitável, é que se desbloquearam alguns debates que fragilizaram o consenso provisório anterior: sobre a cumplicidade de amplos setores da sociedade civil e da Igreja em torno aos crimes cometidos pelo Estado; a respeito da polarização política e da emergência dos grupos de luta armada anteriores ao golpe de 76 (debate por sua vez atravessado pelas distintas leituras do peronismo no país); a respeito do que alguns interpretam como "abusos da memória". Sobretudo no que diz respeito aos dois últimos, tais debates seguem até o presente irreconciliáveis ${ }^{7}$.

Tais conflitos em torno da memória pós-ditatorial, que efetivamente ocuparam o espaço público argentino a partir de meados dos anos 90, parecem, de certa forma, invejáveis para quem os observa a partir da experiência brasileira do esquecimento forçado, sustentado por práticas diversas de apagamento: a manutenção do sigilo que paira ainda

\footnotetext{
${ }^{6}$ A cena televisionada e retransmitida no mundo todo, de militares de alta patente atravessando o corredor de madeira à frente de seus julgadores e respondendo pelos crimes de violação aos direitos humanos, teve um impacto duradouro e fundamental na história recente argentina. Haveria-se que entender as complexas operações em jogo para que fosse possível levar tais julgamentos a termo. Evidentemente, foi necessário que toda a pressão e as ameaças militares que antecederam à realização das Juntas fossem enfrentadas sem temor. Hugo Vezzetti (2012) mostra todo o arsenal de pressão militar mobilizado às vésperas dos julgamentos. Este mesmo autor sublinha ainda que a derrota humilhante do exército argentino na Guerra das Malvinas é um elemento importante para entender o processo que tornou possível os juízos às Juntas Militares.

${ }^{7}$ Contudo, arrisco dizer que tais dissonâncias no conflituoso campo da memória tenderam a baixar de tom uma vez que alguns dos consensos básicos alcançados nos anos 80 começaram a ser questionados pelo macrismo. Lanço esta ideia ainda como uma hipótese inicial, de um estudo por vir.
}

Revista Moara, n. 56, vol. 1, ago-dez 2020 ISSN: 0104-0944 
sobre muitos documentos da ditadura; os poucos e discretos espaços dedicados à memória do período; o bloqueio judicial imposto pela lei da Anistia; a árdua disputa para que se conseguisse estabelecer a mais tardia de todas as Comissões da Verdade do Cone Sul; a privatização dos dramas das famílias de mortos e desaparecidos; a invisibilização dos genocídios que vitimizaram as populações indígenas e as populações periféricas nas cidades ao longo de todo o período; a continuidade das práticas repressivas e de tortura de uma das polícias mais letais do mundo.

É certo que toda memória social é um espaço de disputa, que pressupõe negociações e embates a partir dos quais algo se esquece, para que algo possa ser lembrado. Viu-se como no caso argentino foi preciso "esquecer", pelo menos por certo tempo, os temas que levariam à clivagem do campo progressista para que a reivindicação pela memória das vítimas atrelada às demandas de justiça pudessem se impor, tal como na Alemanha uma memória crítica em relação à ampla adesão social ao nazismo só se mostrou possível mediante certo esquecimento dos bombardeios aliados sobre as cidades alemãs ao final da II Guerra: algo tinha que ser esquecido no debate público para que a política da memória tivesse sucesso em primeiro lugar (HUYSSEN, 2014, p.155176). Também é certo que a memória social é dinâmica e que, em determinados processos de elaboração de traumas coletivos, as fraturas dolorosas podem ser "esquecidas", mas após terem sido reconhecidas socialmente e após encontrarem caminhos de reparação e de elaboração simbólica, como no processo de luto (KEHL, 2010).

No Brasil, contudo, é outro tipo de esquecimento o que acabou se impondo. Ainda que haja o trabalho incansável e fundamental dos familiares das vítimas, ainda que haja uma produção historiográfica profusa e importante a respeito dos anos de chumbo e que, inclusive, haja também um corpus vigoroso de obras que rememoram esse passado recente desde meados dos anos 70 até o presente, em diversas linguagens artísticas (cinematográfica, literária, dramatúrgica, visual), tais materiais não encontram difusão significativa - em outras palavras, não conseguem emplacar de fato uma memória minimamente acordada coletivamente sobre o que deveria ser lembrado, sobre o que não poderia se repetir ou sobre o que deveria e deve ser reparado.

A artista plástica Giselle Beiguelman (2019, p. 216) arriscou pensar nosso medo à memória a partir do desastre que consumiu em chamas o Museu Nacional, em 2018, lendo-o como uma trágica metáfora da tradição memoricida por meio da qual se cons-

Revista Moara, n. 56, vol. 1, ago-dez 2020 ISSN: 0104-0944 
truiu a história da nação: práticas reiteradas de apagamentos diversos pelas quais se delinearam os clichês de um povo harmônico e pacífico, mascarando a cultura de ódios velados e naturalizados ao longo de séculos de escravismo. $\mathrm{O}$ apagamento da memória da ditadura brasileira seria apenas mais um capítulo dessa verdadeira compulsão ao esquecimento.

Ainda que possamos pensar nessa longa duração da desmemória na cultura nacional, seria preciso atentarmos para os aspectos políticos do continuísmo e dos acordos de nossa transição que ajudaram a costurar com muita eficácia a máquina de esquecimento induzido em relação aos crimes de Estado cometidos com a cumplicidade de certos grupos sociais. SegundoVladmir Safatle (2010, p.250-1), a vitória do Partido da Amnésia no Brasil se deve à evidencia de que a democracia que se desenhou no período de transição não foi estável e nem caminhou rumo a um aperfeiçoamento, apresentando uma série de soluções de continuidade entre os acordos políticos que sustentaram a aparência de legalidade durante a ditadura e os rumos tomados pós- $85^{8}$.

A precariedade de uma cultura da memória pós-ditatorial brasileira poderia ser ainda pensada por uma possível precocidade na autocrítica dos grupos revolucionários que, em nosso caso, parece ter favorecido a imposição do silêncio e a ausência de ressonância dos esforços de lembrar. É a hipótese lançada por Seligmann-Silva (2014) ao tratar de obras como Em câmara lenta, de Renato Tapajós (1977), K., de Bernardo Kucinski (2011) e do filme Que bom te ver viva, de Lúcia Murat. Não se trata de um posicionamento consensual, mesmo no campo progressista: Daniel Aarão Reis (2019, p.276), por exemplo, considera que uma ausência de autocrítica é que estaria impedindo as negociações sociais para a construção de uma memória sobre a ditadura civil-militar, já que a produção memorialística literária e acadêmica estaria insistindo em uma imagem épica das esquerdas radicais e moderadas, reunindo-as sob um manto comum da resistência. Esse procedimento faria ignorar a cumplicidade social conquistada pela ditadura e apagaria as divergências entre os diversos grupos de esquerda. Trata-se de um

\footnotetext{
${ }^{8}$ Nesse sentido, pode-se lembrar que a imagem televisionada mais frequentemente difundida como emblemática de nosso passo à democracia foi o momento de promulgação da Constituição de 1988: ao contrário, contudo, da cena judicial argentina (o Juízo às Juntas Militares) e seu forte teor de ruptura, nossa constituição cidadã, ainda que resultante de uma série de conquistas, carrega em seu interior uma gama pouco conhecida de muitos acordos, como o papel conferido aos militares no artigo 142. A busca pela estabilidade política se impôs aos enfrentamentos que seriam necessários para garantir verdade, justiça e um aprofundamento da democracia após a ditadura (ZAVERUCHA, 2010).
}

Revista Moara, n. 56, vol. 1, ago-dez 2020 ISSN: 0104-0944 
debate que demandaria uma análise mais cuidadosa, mas, de todo modo, analisando as operações implicadas, os "esquecimentos" provisoriamente acordados e a periodização dos casos argentino e alemão, a hipótese de Seligmann-Silva parece convincente ${ }^{9}$.

Seja por motivos de longa ou de média duração, as implicações dessa política de "memória impedida", que manteve os traumas sociais em uma zona de recalque, se fazem sentir no presente. Vale lembrar que a teoria psicanalítica do trauma, aplicada a situações de catástrofe social, não entende o esquecimento como uma ausência ou um vazio: trata-se da presença de uma ausência, negada ou silenciada (JELIN, 2018, p. 16). No caso brasileiro, "quando a memória da dor é negada após os pactos de transição, o que ocorre é uma extensão do estado de exceção que perdura no campo da memória", afirma Seligmann-Silva $(2019$, p.4) e no campo dos direitos humanos, pode-se acrescentar.

Mas, volto a dizer, aparentemente estamos hoje vivendo uma mudança de época: há fissuras na barreira que mantinha certos temas silenciados, como o tema da tortura (de ontem e de hoje) dos desaparecimentos e dos assassinatos promovidos pelo Estado, e que voltam a ser difundidos abertamente, não no sentido tão aguardado de verdade e justiça, e sim defendidos, naturalizados e aceitos socialmente.

Voltando o foco às duas cenas comentadas acima - a fala do deputado no congresso brasileiro, atual presidente do Brasil, e a fala do então Ministro da Cultura de Buenos Aires, em 2016 - o que ambas parecem ter mostrado é que, embora em um mesmo cenário de fortalecimento da extrema direita no mundo (favorecido por uma combinação complexa de fatores que não caberia detalhar aqui), há diferenças notáveis entre as condições de possibilidade do dizível e os limites do indizível em cada um dos espaços públicos nacionais, o que tem a ver também com as diferentes forças que conseguiram se impor nas disputas pela memória em cada país: uma manifestação como a que assistimos no congresso brasileiro, na Argentina seria certamente punida como apo-

\footnotetext{
${ }^{9}$ Creio que o desenvolvimento deste debate deveria levar em conta ainda a dificuldade de se imporem no Brasil as narrativas e testemunhos de memória que evidenciam que a violência programada do Estado brasileiro durante a última ditadura não se deu apenas direcionada aos grupos militantes armados, mas que se tratou de uma violência ampla e sistêmica contra o conjunto da sociedade, implicando em etnocídio, em mortes nas periferias urbanas e no campo, mortes decorrentes do desmonte com a saúde pública etc. Pretendo desenvolver esta discussão com base em outros materiais em pesquisa ainda em andamento.
}

Revista Moara, n. 56, vol. 1, ago-dez 2020 ISSN: 0104-0944 
logia do terrorismo estatal, supõe Serra Padrós a partir de outro exemplo ${ }^{10}$ (2012, p.66).

Sem poder dar conta da complexidade de todas estas questões, deixei-as ressoando na proposição deste trabalho, pois na leitura dos romances que me chegaram às mãos mais ou menos nesses mesmos dias de 2016, comecei a vislumbrar os contornos de um conjunto de obras que enlaçam no percurso de seus personagens um passado histórico compartilhado entre Brasil e a Argentina e um trabalho de memória que se faz no deslocamento de um a outro lado da fronteira, de um a outro idioma, sem que estejamos falando propriamente de poéticas do exílio (ainda que o exílio não esteja ausente dessas poéticas). Os romances de Volpato, Fuks e Vidal parecem desenhar trabalhos de elaboração do passado recente que não se submetem aos limites territoriais e identitários da nacionalidade.

Procurarei apresentar uma breve resenha de cada uma das obras para em seguida sugerir a partir delas de que modo seria possível lê-las em um conjunto de memórias em trânsito, como estou propondo.

\section{A ditadura argentina em três romances brasileiros contemporâneos}

Começo com este livro de Cadão Volpato, escritor, músico e ilustrador cuja trajetória literária até agora havia se desenvolvido nos contos. Este seu primeiro romance é dividido em duas partes e uma espécie de epílogo. Na primeira parte, correm em paralelo a história de dois personagens, o taxista argentino Tortoni, que se gabava de conhecer e saber apresentar Buenos Aires como nenhum outro, e o arquiteto brasileiro Rivoli, que viajara com o intuito de conhecer "o fim do mundo", convidando Tortoni a acompanhálo numa viagem à Patagônia. Nessa espécie de road story, um narrador em terceira pessoa nos apresenta capítulos da história de ambos os protagonistas, um em Buenos Aires, o outro em São Paulo, intercalando-os a passagens da viagem que fazem juntos. É o ano de 1969, e o arquiteto Rivoli, sem nunca entender exatamente o que se passava, já conhecera de perto as ameaças da ditadura brasileira: um colega uruguaio do escritório de arquitetura, mais jovem, havia sido preso e torturado por alguns dias, até que o próprio Rivoli, pela interferência de outro colega, conseguisse interceder por ele e soltá-lo.

\footnotetext{
${ }^{10}$ A saia justa criada aos governos de Chile e Argentina com a visita oficial do governante brasileiro parecem reforçar essa ideia.
}

Revista Moara, n. 56, vol. 1, ago-dez 2020 ISSN: 0104-0944 
Rivoli sabe e não sabe do que acontece. No corpo alto e desastrado do brasileiro que se parece um sueco, segundo Tortoni, há uma espécie de constante desajuste. O lirismo com que enxerga o mundo parece fazer dele um Mounsier Hulot, espécie de clowm ingênuo que vai esbarrando nos acontecimentos e avançando entre um desequilíbrio e outro.

Dez anos depois, na segunda parte do livro, o caminho dos dois personagens volta a se cruzar, quando o filho de Tortoni, perseguido pela ditadura argentina, refugiase com a namorada na casa da família de Rivoli. Nesta segunda parte, o arquiteto está presente em toda a narrativa, mas, sem que o narrador o explicite em nenhum momento, é apenas um espectro que desconhece sua própria condição de morto.

Como em uma composição simbolista, desenham-se elementos que se oferecem à percepção e se esvaem no momento seguinte. Há uma espécie de atmosfera densa e um círculo de ameaças que aparentemente vai se fechando sobre eles: um carro de polícia que ronda a casa da serra onde se escondeu o jovem casal montonero; os vizinhos desconfiados dos forasteiros que falam espanhol; um delegado que faz perguntas insistentes sobre os estrangeiros abrigados pela família; luzes de farol de um automóvel que devassam o espaço doméstico... O relato parece sugerir, pela sobreposição de cenas e ameaças, a proximidade de um desenlace trágico. Como adverte Rodrigo Naves, contudo, essa expectativa se dissolve em outros arranjos: "o choque frontal e ruidoso entre as forças centrais da sociedade, faltou ao encontro marcado". Há uma reorganização sem que a ameaça seja consubstanciada e as histórias cruzadas dessas duas famílias em Buenos Aires e São Paulo retoma seu curso, ainda que transformadas por estes encontros em um futuro pós-utópico. Não há final trágico, nem épico nem redentor. Ficam marcas e alguns traumas serão carregados por personagens marginais na trama, mas as cifras desse passado dissolvem-se em um mundo de sonhos.

O romance A resistência, de Julián Fuks, por sua vez, poderia ser identificado inicialmente como autoficção, a partir do enlace de elementos ficcionais a referentes extra-literários amalgamados à figura do autor fora do texto. Aqui, o protagonista narrador, filho de um casal de médicos psiquiatras argentinos, exilados em São Paulo na passagem dos anos 70 aos anos 80, cria um caminho pela memória familiar, que ele investiga em busca de uma aproximação com o irmão adotivo.

Desde o início, a resistência consubstanciada no título projeta-se sobre as múlti-

Revista Moara, n. 56, vol. 1, ago-dez 2020 ISSN: 0104-0944 
plas camadas da narrativa: a resistência explícita na militância política dos progenitores; a resistência implícita no exercício da paternidade e da maternidade em uma situação completamente adversa; a resistência do irmão, no contexto familiar; a resistência de um passado que se recusa deixar reconstruir. Tratam-se das dificuldades inerentes a uma busca que se pode fazer apenas por lembranças dissonantes de diferentes sujeitos; por fragmentos de imagens, pequenos retângulos fotográficos que registraram um lapso de tempo, que para serem lidos requerem a interpretação daquele que a observa; pela colagem imperfeita de uma marchetaria construída com peças desiguais; o atrito das palavras que resistem a entregar aquilo que se busca: o relato que não se deixa escrever.

Em busca de mais elementos que possam dar pistas desse passado familiar, o protagonista recria lembranças da infância em São Paulo, na companhia dos irmãos e dos pais, mas a decisão da escrita se revela sobretudo no translado à Buenos Aires, cidade onde o autor se refugia para escrever, imerso em lembranças que não são dele em meio a longas caminhadas.

Em uma cena que eu gostaria de destacar, o narrador procura o apartamento em que moraram seus pais e no qual seu irmão passou os primeiros meses de vida. Mesmo sabendo que muito provavelmente não poderá entrar, procura o prédio na esquina das ruas Junín e Peña e, após alguma hesitação, aperta o interfone. Ao ser recebido pelo porteiro, o narrador pergunta se ele tem notícia de um casal que viveu no prédio, com um bebê, nos anos 70, e que teve que sair às pressas. $\mathrm{O}$ porteiro, ainda algo incrédulo lhe pergunta se ele não sabe seus nomes. Sim, claro, ele sabe: o casal que procura são seus pais, que não desapareceram, e o bebê é seu irmão, hoje um adulto. "Só queria conhecer o apartamento onde viveram porque estou escrevendo um livro a respeito (...)" (p. 57-8)

Pela primeira vez consigo do porteiro alguma reação, pela primeira vez seu rosto lento se contorce numa expressão imprevista, que só decifro quando ela se traduz numa golfada de desdém. Ah, una más, una memória más de los setenta, ele diz já em movimento, escancarando a porta e me apresentando ao saguão, meneando o braço num gesto largo e solene, adelante, usted pase, haga lo que quiera. Mas eu não me movo, fico parado diante daquele pórtico antigo, daquelas paredes cinza, e não sei mais o que dizer. A paralisia se expandiu do meu peito, tomando meus pés e minhas mãos até a ponta dos dedos. Essa é a integridade que consigo, a paralisia é meu corpo inteiro. (p. 58)

Há uma série de distâncias (de classe, de visões de mundo, de experiências) que separam os dois personagens, crispando o diálogo em desconfianças mútuas. A eficácia

Revista Moara, n. 56, vol. 1, ago-dez 2020 ISSN: 0104-0944 
da cena parece potencializar-se justamente porque as poucas palavras trocadas entre o escritor e o porteiro multiplicam em vários níveis os desacordos entre ambos. Há um traço irnônico que sublinha a passagem, quando o escritor assiste a seu projeto (que guarda a ambição da singularidade de uma escrita) ser lançado em uma vala comum de "outras memórias a mais dos setenta" - os sonhos e as dores de uma época desprezados no gesto soberbo do interlocutor. A paralisia do narrador parece não apenas recusar a indiscrição do outro que avança sobre o espaço íntimo de sua história, mas também faz ecoar o desconcerto do personagem mediante o diálogo inesperado: no cenário de uma portaria brasileira, talvez a conversa se mostrasse inverossímil.

O terceiro romance que gostaria de comentar brevemente, Mar Azul, foi publicado em 2012, e é o segundo romance de Paloma Vidal, também autora de livros de contos e de outros escritos de mais difícil classificação, como Ensaio de vôo (2017) e a reunião de seus poemas e fragmentos no blog Lugares onde não estou. Sua poética, bastante atravessada pelo tema das viagens e do trânsito entre paisagens e línguas, incorpora muitas vezes a partir do registro autoficcional, um trajeto "mais ao Sul" de um a outro lado do Prata (CHECCHIA, 2019). Mar Azul, no entanto, trabalha este trajeto por meio de personagens ficcionais.

Em um fragmento do diálogo que abre este romance, uma das personagens afirma à sua amiga, jovem como ela: "se eu fosse escrever um livro, ia escrever sobre quando eu ficar velha", e pergunta em seguida "Você pode se imaginar daqui cinquenta anos?" (VIDAL, 2012, p.16). Nestas duas linhas parece estar cifrado um dos mecanismos de composição deste romance, cujo enredo se desenvolve por uma narrativa em primeira pessoa, de uma personagem velha que vai recompondo, entre observações de seu cotidiano solitário, os fragmentos de sua própria história.

A trama não se dá a ver toda de uma vez. Apenas muito lentamente vai-se desenhando uma cronologia, que se oferece a partir de algumas lembranças, poucas datas e da leitura que faz a personagem das anotações crípticas que o pai deixara em diversos cadernos.

A partir deste quebra-cabeça, o leitor entende que os diálogos que abrem o romance se davam entre duas meninas que cresceram em um bairro de classe média de Buenos Aires, sua amiga Vicky e ela mesma, a narradora. Esta última, já órfã de mãe, fora abandonada pelo pai ainda na adolescência e, por isso, passou a morar com Vicky e 
sua mãe.

Nas reflexões da personagem, diversas vezes um pensamento começa com: "se Vicky estivesse aqui...”. Nesta espécie de estribilho é reiterado o vazio do desaparecimento, do luto que não pode se completar. Meses após o desaparecimento da amiga, em 1976, a protagonista viajara para a cidade do Rio de Janeiro, onde recomeçou a vida neste novo idioma que adotou como seu. Junto com as lembranças da amiga, a personagem tenta lidar também com a ausência do pai, que deixou a Argentina após a queda do peronismo, dirigindo-se à Brasília, onde participou da construção da nova capital. O pai era "uma assinatura no pé de algumas cartas", algumas lembranças, muitas perguntas, "uma suspensão": um abandono.

A narradora encontrou no novo idioma e na cidade que adotou, uma leveza que não tinha no mapa de medos de sua cidade natal e nos interditos do idioma que foi seu até metade da vida. $\mathrm{O}$ corpo velho da personagem que caminha no presente sobre a cidade adotada, o Rio, conhecendo-a pelos pés, experimenta as limitações da velhice, mas também um crescente tatear de liberdade vivenciada na escrita e na água clorada da piscina.

A escrita desta personagem se espraia no verso das páginas escritas dos cadernos deixados pelo pai, que fôra registrando neles o que a mente ia perdendo para a doença. A narradora escreve porque o pai escreveu um dia. Escreve porque é preciso preencher o verso dessas páginas.

O relato faz surgir assim uma composição palimpsestíca, pela qual a escrita do presente interfere nos restos do passado, bem como, em sentido inverso, só se apresenta como possível mobilizada por estes restos e interferida por eles. Trata-se de uma composição levada ao extremo quando a personagem arrisca-se, vencendo certo pudor, a escrever diretamente sobre os registros do pai, e não apenas no verso da página. A letra de ambos é semelhante e poderia ser facilmente confundida por quem não estivesse precavido dos distintos autores das notas. As páginas desses cadernos compartilhados sugerem um portal pelo qual as distintas camadas temporais percorridas por pai e filha, em sua passagem da Argentina ao Brasil, se misturam e se encontram, produzindo uma aproximação da qual o pai parece ter sempre se esquivado. Ao mesmo tempo, a escrita de um sobre a do outro perturba mutuamente a legibilidade do passado e do presente.

Deste romance gostaria de destacar a cena em que a protagonista, ao chegar à 
portaria do prédio em que morava, encontra-se com o porteiro - novamente um porteiro, este guardião entre o espaço público e privado-, que lia no jornal uma notícia sobre o ditador argentino octogenário. O porteiro mostra a ela a notícia e pergunta se é sobre seu país. Ela diz que sim. Sobre a foto do ditador, a matéria ostenta a manchete que ela precisa retraduzir mentalmente à outra língua, ao espanhol, como se lê-la em português não fosse suficiente para que ela entendesse. A matéria diz que o general não se arrepende de nada. A protagonista pode imaginá-lo pela foto, seguro de seus protocolos, estreitando nas mãos uma pastinha azul na qual, talvez, algumas anotações escritas em próprio punho guardassem suas certezas. Ele não se arrepende de nada e suas palavras são reproduzidas na reportagem: "desaperecidos figura cómoda".

A cena é concluída: "Seu José está em silêncio. Tem os olhos sobre o jornal. Ele também está velho. Deve ser apenas um pouco mais jovem do que eu. Quando levanta a vista me pergunta o que é um desaparecido" (VIDAL, 2012, p.170).

Não se pode conhecer o desenrolar desse diálogo, mas, em contraste aos obstáculos entre os personagens enfrentados no trecho de $A$ resistência, aqui se pode ver um movimento de abertura de um personagem ao mundo desconhecido da outra, a velha argentina.

\section{Algumas linhas exploratórias do conjunto, voltando a pensar as memórias em trânsito}

Numa tentativa de desenhar este corpus, procuro agora traçar alguns contornos que poderiam reuni-los, guardados em suas singularidades, a partir da ideia das memórias em trânsito.

Em um primeiro nível, o corpus proposto ajuda a reforçar o marco regional que conecta os processos históricos das ditaduras civis-militares e das transições do Cone Sul apesar das singularidades irredutivelmente nacionais de cada contexto político no que tange aos embate em torno à memória, retomando uma tradição crítica latinoamericana que sublinha a insuficiência dos limites nacionais para a compreensão dos fenômenos históricos e culturais no continente (PIZARRO, 2004). Apoio-me ainda na observação de Seligmann-Silva (2014, p.14) quando afirma ser "Impossível tratar desse tema da memória pós-ditatorial no Brasil sem falar de seus vizinhos”.

Revista Moara, n. 56, vol. 1, ago-dez 2020 ISSN: 0104-0944 
Além de tal amplitude regional, contudo, seria preciso pensar as "memórias em trânsito", ou algumas de suas variantes - memórias viajantes, transnacionais ou transculturais - também sob o marco ampliado dos estudos sobre o imaginário e memória cultural, que, tencionados pela crise do Estado-nação ao final do séc.XX, pela expansão dos movimentos migratórios e às múltiplas formas de translocalidades (APPADURAI, 1997), passaram a atribuir cada vez mais relevância ao conceito de deslocamento (PALMERO GONZÁLEZ, 2010, p.109). Os limites do nacionalismo metodológico, que por tanto tempo organizou os estudos da memória, foram se mostrando cada vez mais evidentes e, a partir de concepções mais fluidas da territorialidade das culturas, tornaram-se mais visíveis as rotas que conectam distintos processos do lembrar-esquecer (ERLL, 2011).

A tais questionamentos somaram-se as investigações sobre a cultura de massas no contexto globalizado e sobre algumas práticas que podem ser vistas também a partir das dinâmicas transnacionais mobilizadas em um mercado cultural da memória, hiperconectado sobretudo a partir dos anos 80 e 90 (HUYSSEN, 2014).

Assim, sob esta dupla moldura (regional e transnacional), nos três relatos aqui reunidos os restos do passado ditatorial do Brasil e da Argentina parecem emergir sempre de um deslocamento, de percursos e trajetos que rompem com as demarcações nacionais, reinventando a longa tradição da literatura viajante. Espaços e cidades são enlaçados nos trajetos e lembranças de seus protagonistas, lembranças estas que se produzem em e a partir dos deslocamentos. Em São Paulo, Buenos Aires, Rio de Janeiro ou no hotel do fim do mundo, as cidades tem sua densidade histórica plasmada na trama de relatos que se cruzam, tecidos por personagens em trânsito que as conectam. Novos arquivos literários parecem se desenhar dessas escritas, que mobilizam um leitor igualmente nômade, convidado a esses itinerários "mais ao sul"11.

Mas é possível pensar em tais memórias em trânsito também em outro âmbito, lembrando que as noções de identidade e de sujeito também têm sido vistas sob a ótica da mobilidade. Nos romances em vista, as memórias construídas nos relatos não restituem a completude e unidade de um sujeito e, antes, evidenciam sua fragmentação e provisoriedade: o arquiteto em permanente desequilíbrio, quando não seu espectro; o

\footnotetext{
${ }^{11}$ Título de um dos livros de contos de Paloma Vidal.
} 
escritor em busca de um relato impossível; a velha buscando narrar sua vida a partir dos fragmentos dispersos dos escritos do pai em sua luta contra o Alzheimer (ou outra doença semelhante). Não há identidade prévia a resgatar e nem memórias que a devolvam.

É fato que todo processo de memória pode ser visto como fragmentário, incompleto e sob permanente reconfiguração a partir de vestígios diversos, próprios e alheios. Talvez seja o paradoxo irredutível da memória, mas em tais literaturas o vazio de origem e a ausência de um porto ao qual retornar se façam sentir com mais evidência, sublinhando de múltiplas formas a tradição crítica da modernidade e a instabilidade do terreno no qual o sujeito contemporâneo em vão busca se configurar. Esse impulso à errância parece distanciar os personagens e seus relatos da tradição das literaturas do exílio nas quais a dimensão trágica do deslocamento abrupto e forçado parece trazer consigo um lastro de origem e uma expectativa de retorno, mesmo quando frustrada.

Vale ainda dizer que nos três casos não há uma linha delimitadora evidente entre o domínio da memória pública, coletiva e o domínio da memória individual, o que as mostra em sintonia a outras práticas das artes contemporâneas que rasuram o arquivo como repositório positivo e público de uma coletividade formada a priori (como a nação) (PEDROSA et alli, p. 18). Nas tramas familiares destes romances, a história íntima encontra-se entranhada à história política recente argentina e brasileira, atando-as. Esta articulação, contudo, não se dá a partir do que se costuma chamar "contexto histórico" ou "pano de fundo", tela plana sobre a qual se pintariam as trajetórias das famílias. Ao contrário, esse passado político também se dá a ver de modo fragmentário, elíptico a partir de diferentes percepções, distintas trajetórias e numa disputa de significados que permanece ressoando no presente.

A crítica Florência Garramuño chama a atenção para os modos de ativação dos restos do passado nas práticas estéticas contemporâneas, que promovem uma montagem de tempos heterogêneos que revelam a porosidade das diferentes épocas, para além da necessidade de recordar. Segundo ela, a lógica de sobrevivência fantasmal de vestígios fragmentários é bastante distinta da lógica reconstrutiva da recordação que predominou nos registros memorialísticos das últimas décadas: "estas práticas parecem eleger, frente à reconstrução que supõe a memória, o trabalho com restos e vestígios que em lugar de

Revista Moara, n. 56, vol. 1, ago-dez 2020 ISSN: 0104-0944 
recordar ativa uma sobrevivência amiúde fantasmal e paradoxal" (GARRAMUÑO, 2016, p.3, minha tradução) ${ }^{12}$.

A chave em que tais obras são lidas, portanto, parece estar mudando. Em poucas palavras, se até há pouco tempo atrás podia-se pensar no predomínio de práticasmemória, (pós-trauma), ainda que pelas vias truncadas e complexas do luto, mais recentemente, e talvez ainda mais à luz dos acontecimentos recentíssimos mencionados no início, tais textos assumem outro lugar, iluminando processos inconclusos, sublinhando a evidência de vastas zonas de sombra que continuam a pulsar no presente: práticasvestígio.

Pode-se pensar ainda no trânsito das línguas que pressupõem os deslocamentos nestes relatos. Em Pessoas que passam pelos sonhos, o espanhol é a língua que invariavelmente desperta a atenção das forças repressoras brasileiras, pois parece guardar a memória de um horizonte de mudanças compartilhado pela juventude de todo continente nos anos 60 e 70: em uma de suas cenas ao final do romance, logo antes do desenlace, as personagens encontram uma espécie de redenção na festa em que se reúnem ao som de "Canción para mi muerte", do grupo argentino Sui Generis.

Mas o deslocamento entre línguas pressuposto nestas memórias em trânsito parece uma questão especialmente importante em Mar Azul e A resistência, cujos autores, não casualmente, são filhos biográficos e literários de dois idiomas, em virtude do trajeto familiar que os precedeu (o exílio dos pais).

Nesse sentido, retomo as cenas citadas acima, os dois diálogos das personagens protagonistas com os porteiros, que podemos ler à luz de sua potência dialógica e política (FIORIN, 2009, p.151-2). Na primeira cena, o escritor brasileiro não encontra caminhos por onde fazer avançar o diálogo na outra língua, ainda que seja sua língua também. Sua paralisia, parece ser expressiva de um desentendimento muito mais profundo, que remete às reflexões acima sobre os não ditos da memória no Brasil e o terreno explícito de disputas da memória na Argentina.

No caso da segunda cena, em Mar Azul, a distância entre as línguas parece, ao contrário, promover a aproximação. Uma palavra incapaz de se impor no uso comparti-

\footnotetext{
12 estas prácticas parecen elegir, frente a la reconstrucción que supone la memoria, el trabajo con restos y vestigios que en lugar de recordar activa una supervivencia a menudo fantasmal y paradójica (GARRAMUÑO, 2016, p.3).
}

Revista Moara, n. 56, vol. 1, ago-dez 2020 ISSN: 0104-0944 
lhado que uma comunidade faz da língua para descrever o mundo é sinal de que uma parte deste mundo é invisível à comunidade que o descreve. Porém, a cena evidencia um diálogo entre falantes de dois universos discursivos que se põem em contato, recriando-se mutuamente. Desta interação complexa uma palavra "vazia" de significados no universo de representações de um dos falantes, desaparecido, será perturbada e tensionada pelo horizonte de representações e de experiências envolvidas pelas palavras da outra falante. Desta interação viva de vozes e dos diferentes ritmos da memória social incorporadas nas duas personagens, a ampliação de sentidos se mostra como uma pequena e importante vitória das forças centrífugas da linguagem sobre as forças que buscam restringir as possibilidades de entendimento do real.

Estas duas cenas podem funcionar também como metáforas das distintas formas com que os processos de memória no Brasil se ressignificam quando examinados à luz de seus vizinhos e quando vistos neste conjunto, por meio de personagens criados a partir de múltiplos pertencimentos.

Em suma, seria possível pensar que nos três casos há uma memória, ou, melhor dizendo, um trabalho com os restos, que se organizam a partir do trânsito e do percurso que conecta em uma dimensão nova as histórias de Brasil e Argentina e de suas respectivas literaturas, fazendo lembrar, como disse Daniel Link (2002, p.13) "que os limites de uma comunidade de leitores (os limites da literatura, os limites da leitura) não coincidem necessariamente com os limites estatais que herdamos do século XIX”.

Por rotas alternativas, os processos bloqueados da memória ditatorial brasileira, pelo menos no plano simbólico, parecem encontrar novos caminhos de elaboração a partir das produções artísticas que o conectam aos seus vizinhos. Ganhando efeitos não previstos no contexto de sua publicação, os relatos aqui examinados acabam por participar de um esforço em múltiplas vozes contra o revisionismo a que se assiste no presente. Ademais, ainda que seja cedo para uma resposta, o exame das dinâmicas da memória e suas conexões entre distintos contextos, permite-nos perguntar se o esforço revisionista atualmente em curso é tão controlável quanto esperam as atuais forças que sustentam o governo da destruição.

Revista Moara, n. 56, vol. 1, ago-dez 2020 ISSN: 0104-0944 


\section{REFERÊNCIAS}

APPADURAI, Arjun. Soberania sem territorialidade - notas para uma geografia pósnacional. Novos Estudos Cebrap, nº49, p.33-46. Disponível em:

https://edisciplinas.usp.br/pluginfile.php/236363/mod_resource/content/1/Appadurainotas_para_uma_geografia.pdf. Último acesso em: 23 abril 2020.

BAUER, Caroline Siveira. Brasil e Argentina: ditaduras, desaparecimentos e políticas da memória. Porto Alegre: Medianiz, 2014.

FICO, Carlos. Violência, trauma e frustração no Brasil e na Argentina: o papel do historiador. Topoi, Rio de Janeiro , v. 14, n. 27, p. 239-261, dez. 2013. Disponível em <http://www.scielo.br/scielo.php?script=sci_arttext\&pid=S2237-

$101 X 2013000200239 \& \operatorname{lng}=$ pt\&nrm=iso $>$. Acesso

em: 13 jun 2020. https://doi.org/10.1590/2237-101X014027003.

FIORIN, José Luiz. Língua, discurso e política. Alea, Rio de Janeiro, v.11, $\mathrm{n}^{\circ} 1$, jan-jun. 2009, p.148-165. Doi: http://dx.doi.org/10.1590/S1517-106X2009000100012. Disponível em: <http://www.scielo.br/scielo.php?script=sci_arttext\&pid=S1517-

106X2009000100012\&lng=en\&nrm=iso>. Acesso em: 25 jul 2019.

FUKS, Julián. A resistência. São Paulo: Companhia das Letras, 2015.

BEIGUELMAN, Giselle. Beleza compulsiva tropical. In Memória da amnésia: políticas do esquecimento. São Paulo: Edições SESC, 2019, p. 212-231.

DALMARONI, Miguel. La palabra justa - literatura, crítica y memória en la Argentina 1960-2002. Mar del Plata: Melusina; Santiago de Chile: Ril, 2004.

ERLL, Astrid. Traumatic pasts, literary afterlives, and transcultural memory: new directions of literary and media memory studies. Journal of Aesthetics \& Culture, vol 3, 2011. Disponível em: https://www.tandfonline.com/doi/full/10.3402/jac.v3i0.7186. Acesso em: 25 nov 2019.

GARRAMUÑO, Florencia. Sobrevivencias y fantasmas contemporáneos - otras formas de la memória. Ponencia presentada en el Seminario La constitución dinámica de la Memoria Cultural - Prácticas estéticas y redemediatizaciones. México: DF, UNAM, 2016. Disponível em:

https://www.academia.edu/25728515/Sobrevivencias_y_fantasmas_contemporáneos._O tras_formas_de_la_memoria. Acesso em: 8 de dez de 2019.

HUYSSEN, Andreas. Culturas do passado-presente - modernismos, artes visuais, políticas da memória. Tradução de Vera Ribeiro. Rio de Janeiro: Contraponto / Museu de Arte do Rio, 2014.

JELIN, Elizabeth. La lucha por el pasado - cómo construímos la memória social. Buenos Aires: Siglo XXI, 2018.

Revista Moara, n. 56, vol. 1, ago-dez 2020 ISSN: 0104-0944 
KEHL, Maria Rita. Tortura e sintoma social. In TELES, Edson e SAFATLE, Vladimir (orgs.). O que resta da ditadura. São Paulo: Boitempo, 2010, p.123-132.

LINK, Daniel. Como se lê e outras intervenções críticas. Tradução de Jorge Wolff. Chapecó: Argos, 2002.

LUDMER, Josefina. Aqui América Latina - uma especulação. Tradução de Rômulo Monte AltoBelo Horizonte: UFMG, 2013.

PALMERO GONZÁLEZ, Elena. Deslocamento/Desplaçamento. In: BERND, Zilá (Org.) Dicionário das mobilidades culturais - percursos americanos. Porto Alegre: Literalis, 2010, p.109-145.

PEDROSA, Célia [et.al] (orgs). Indicionário do contemporâneo. Belo Horizonte: UFMG, 2018.

PIZARRO, Ana. ¿Diseñar la história literaria hoy? In El sur y los trópicos - ensayos de cultura latino-americana. San Vicente del Raspeig: Universidad de Alicante, 2014, p.4153.

REIS, Daniel Aarão. As armadilhas da memória e a reconstrução democrática. In: ABRANCHES et al. Democracia em risco: 22 ensaios sobre o Brasil de hoje. São Paulo: Companhia das Letras, 2019, p. 274-286.

SABATÉS, Paula. Los artistas contra Lopérfido. Página 12, 22 de mayo de 2016. Disponível em https://www.pagina12.com.ar/diario/sociedad/3-299962-2016-05-22.html

SAFATLE, Vladimir. Do uso da violência contra o Estado ilegal. In: TELES, Edson e SAFATLE, Vladimir (orgs.). O que resta da ditadura: a excessão brasileira. São Paulo: Boitempo, 2010, p. 237-252.

SELIGMANN-SILVA, Márcio. Imagens precárias: inscrições tênues de violência ditatorial no Brasil. Estudos de Literatura brasileira contemporânea, Brasília, nº43, p.13-34, jun. 2014. Doi: http://dx.doi.org/10.1590/S2316-40182014000100002. Disponível em <http://www.scielo.br/scielo.php?script=sci_arttext\&pid=S2316$40182014000100002 \& \operatorname{lng}=$ pt\&nrm=iso>. Acesso em: 18 maio 2019.

SERRA PADRÓS, Enrique. Ditadura brasileira: verdade, memória... e justiça? Historiæ, Rio Grande, v.3, n³, p.65-84, 2012. Disponível em:

https://periodicos.furg.br/hist/article/viewFile/3262/1939. Acesso em: 13 jul 2019.

SONDERÉGUER, María. Los relatos sobre el pasado reciente en Argentina: una política de la memoria. In: Observatorio memoria y praxis social en derechos humanos, Universidad Nacional de Quilmes, Iberoamericana, n. 1 (segunda etapa) AméricaLatina-España-Portugal. Madrid, p.12-13, 2001. Disponível em: <http://www.observatoriomemoria.unq.edu.ar/publicaciones/iberoamericana.pdf $>$. Acesso em: 10 abr 2017. 
VEZZETTI, Hugo. Pasado y presente - guerra, dictadura y sociedad en la Argentina. Buenos Aires: Siglo XXI, 2012.

VIDAL, Paloma. Mar azul. Rio de Janeiro: Rocco, 2012.

VOLPATO, Cadão. Pessoas que passam pelos sonhos. São Paulo: Cosac Naify, 2013.

ZAVERUCHA, Jorge. Relações civis-militares: o legado autoritário da Constituição brasileira de 1988. In: TELES, Edson e SAFATLE, Vladimir (orgs.). O que resta da ditadura: a excessão brasileira. São Paulo: Boitempo, 2010, p.41-76.

Revista Moara, n. 56, vol. 1, ago-dez 2020 ISSN: 0104-0944 